\title{
ESCOLA E EDUCAÇÃO FÍSICA: MAQUINARIA DISCIPLINAR, BIOPOLÍTICAE GENERIFICANTE
}

\author{
DR. MARCELO MORAES E SILVA \\ Mestre em Educação pela Universidade Federal do Paraná \\ Doutor em Educação pela Universidade Estadual de Campinas \\ Pós-Doutorando em Educação na Física Universidade Federal do Paraná \\ (Curitiba - Paraná - Brasil) \\ E-mail: moraes_marc@yahoo.com.br
}

\section{RESUMO}

O presente trabalho procura mostrar como o processo de escolarização e a disciplina de Educação Física ajudaram a produzir e engendrar comportamentos masculinos e femininos. Para alcançar tal intento, apoia-se nas estratégias de análises genealógicas de Michel Foucault. A título de conclusão, o trabalho aponta que a Educação Física, através das práticas de Ginástica e de Esporte, contribuiu significativamente para a construção desse modelo dual nos processos de escolarização.

PALAVRAS CHAVES: Escola; Educação Física; biopolítica; gênero. 
Há algum tempo, determinadas práticas educativas são dirigidas aos seres humanos, a partir de características sexuais e anatômicas. Ter um pênis, testículos ou uma vagina leva automaticamente os indivíduos à prática de certas atividades escolares. A Educação Física participou, e ainda participa, ativamente desse processo, o que produz a separação entre meninas e meninos na esfera cultural.

A partir deste entendimento, este artigo busca compreender como a instituição escolar e a disciplina de Educação Física participaram historicamente da produção de comportamentos masculinos e femininos. Para operacionalizar tal discussão, o texto apoia-se metodologicamente nas reflexões genealógicas de Foucault,' pois estas ajudam a entender quais foram as relações de saber e de poder que possibilitaram o surgimento das diferenças biológicas entre homens e mulheres, além de permitirem visualizar que as construções culturais de gênero não são tão "naturais" como aparentam.

Assim, o artigo divide-se em cinco partes. Na primeira, exploram-se as conceituações de disciplina ${ }^{2}$ e de biopolítica levantadas por Foucault. Na segunda, tais definições são relacionadas com a instituição escolar, buscando visualizar como esta tornou-se uma maquinaria ${ }^{3}$ generificante. A terceira parte, por sua vez, aborda os aspectos generificantes em sua articulação com a disciplina escolar de Educação Física, principalmente a relação desta com seu primeiro conteúdo sistematizado: a Ginástica; ao passo que o quarto tópico problematiza tais aspectos ao conteúdo Esporte. Por fim, o texto procura demonstrar que, a partir da década de 1980, novos elementos surgiram no cenário, ampliando, com isso, as possibilidades de se pensar a Educação Física para além da dicotomia de gênero e da matriz heterossexual.

I. Segundo Veiga Neto (2004), não existe um método foucaultiano propriamente dito, a menos que se torne a palavra método num sentido mais livre do que os atribuídos a esse termo pelo pensamento moderno. Trata-se mais de uma inspiração filosófica do que uma metodologia específica.

2. Veiga Neto (2006) salienta que as disciplinas funcionam como códigos de permissão e interdição. Elas trabalham como um substrato de inteligibilidade para variados códigos e práticas, segundo os quais se dão determinadas disposições, aproximações, afastamentos, limites, hierarquias e contrastes, de maneira que por si só, silenciosamente, elas não apenas engendram maneiras de perceber o mundo e de atuar sobre ele, como também separam o que é considerado "verdadeiro" daquilo que não é.

3. Segundo apontam Álvarez-Uria e Varela (1991), a maquinaria escolar se refere a uma complexa engrenagem formada por um conjunto de máquinas e peças que compõem aquilo que denominamos de escola. Tal conjunto pode ser entendido como uma série de práticas discursivas e não-discursivas que, ao se articularem, criam verdades sobre os indivíduos (crianças), constituindo-os e disciplinando-as dentro de padrões sociais, espaciais e temporais específicos. Nessa mesma linhagem de pensamento, Pineau et. al (2005) chama a escola de uma grande "máquina de educar", uma tecnologia massiva de grande alcance populacional, ou seja, um poderoso artefato para dominar e enclausurar a natureza infantil. 
A fase genealógica de Foucault foi uma continuação dos seus primeiros trabaIhos. Se nos estudos arqueológicos o autor restringia-se ao enfoque discursivo, na genealogia Foucault expandiu suas análises, evocando além do enfoque discursivo as dinâmicas das relações de poder. Duarte (2008) argumenta que a fase genealógica de Foucault procurou redesenhar a trajetória do poder que se desenvolveu no ocidente, a partir do final do século XVI. $\bigcirc$ autor lembra que essa mesma fase dividiu-se em dois momentos que, embora similares, apresentavam algumas diferenciações. O primeiro deles, denominado de poder disciplinar, foi detalhado no livro "Vigiar e Punir" (FOUCAULT, 2002). O ponto de partida era, então, a descoberta dos micropoderes disciplinares, que visavam à administração do corpo individual, surgidos no século XVII, em concordância com a gradativa formação de um conjunto de instituições como a escola, o hospital, a fábrica, entre outros espaços. Em um segundo momento, a partir da publicação da "Vontade de Saber" (FOUCAULT, 1998), abre-se uma nova área de pesquisa genealógica, visto que Foucault elabora os termos biopolítica e biopoder. ${ }^{4}$ Esses conceitos vislumbraram o aparecimento - ao longo do século XVIII e, principalmente, na virada para o século XIX -, de um poder disciplinador, que já não se exercia somente sobre os corpos individualizados, mas também a título de política estatal que pretendia administrar toda a vida e o corpo da população.

Esse poder sobre a vida desenvolveu-se a partir do século XVII, em duas formas princi-
pais; que não são antitéticas e constituem, ao contrário, dois pólos de desenvolvimento
interligados por todo um feixe intermediário de relações. Um dos pólos, o primeiro a ser
formado, ao que parece, centrou-se no corpo como máquina: no seu adestramento, na
ampliação de suas aptidões, na extorsão de suas forças, no crescimento paralelo de sua
utilidade e docilidade, na sua integração em sistemas de controle eficazes e econômicos
- tudo isso assegurado por procedimentos de poder que caracterizam as disciplinas:
anátomo-política do corpo humano. O segundo, que se formou um pouco mais tarde,
por volta da metade do século XVIII, centrou-se no corpo espécie, no corpo transpassado
pela mecânica do ser vivo e como suporte dos processos biológicos: a proliferação, os
nascimentos e a mortalidade, o nível de saúde, a duração da vida a longevidade, com
todas as condições que podem fazê-los variar; tais processos são assumidos mediante
toda uma série de intervenções e controles reguladores: uma biopolítica da população.
(FOUCAULT, I998, p. I5I- I52).

4. Existe na literatura um debate sobre as diferenças e as semelhanças dos termos biopolítica e biopoder na obra de Foucault. Alguns/algumas intelectuais trabalham como termos dependentes, ao passo que outros (as) como se fossem termos independentes. Contudo, tendo em vista o foco do presente artigo, tais pormenores não serão explorados no presente texto. 
Duarte (2008) lembra que foi unindo essas duas formas de poder, que um controle mais efetivo sobre os corpos começou a ser implementado. $O$ autor salienta que, a partir da biopolítica, não importava somente disciplinar a conduta individual. O objetivo passava a ser a implantação de um gerenciamento planificado da vida das populações, mais do que produzir apenas o indivíduo dócil e disciplinado, era necessário gerir a vida da população.

\begin{abstract}
Trata-se de um poder que se aplica a vida dos indivíduos; mesmo que se fale dos corpos dos indivíduos, o que importa é que tais corpos são tornados naquilo que eles têm em comum: a vida, o pertencimento a uma espécie. Se o poder disciplinar fazia uma anátomo-política do corpo, o biopoder faz uma biopolítica da espécie humana. Trata-se de uma biopolítica porque os novos objetos de saber que se criam "a serviço" do novo poder destinam-se ao controle da própria espécie, e a população é o novo conceito que se cria para dar conta de uma dimensão coletiva que, até então, não havia sido uma problemática no campo dos saberes. (VEIGA NETO, 2004, p. 87).
\end{abstract}

Se não há contradição entre poder disciplinar e biopoder, os quais têm sua base comum nos processos de normalização, ${ }^{5}$ não se pode deixar de notar que a introdução da biopolítica impôs uma mutação no curso das pesquisas genealógicas de Foucault. Nessa nova configuração, é importante lembrar que foi através da articulação das duas modalidades de poder que se efetuou um controle mais efetivo sobre os corpos, implantando, tal como exposto anteriormente, um gerenciamento total e planificado das populações. Ou seja, mais do que produzir o corpo docilizado e disciplinado, era importante organizar racionalmente a espécie. E, para realizar tal empreitada, uma instituição chamada "escola" ganha um papel de destaque.

MAQUINARIA I: ESCOLA

Segundo salienta César (2004), foi nesse momento histórico analisado por Foucault, que diversos setores da sociedade foram se "pedagogizando". ${ }^{6}$ Era neces-

5. A norma é o instrumento articulador, tanto nos mecanismos individuais (poder disciplinar) como nos que atuam sobre a população (biopolítica), pois aquela foi o elemento que pôde ser aplicado tanto ao corpo que se quer disciplinar, quanto à população que se quer regulamentar. Segundo Veiga Neto (2004), a norma é o elemento que individualiza, mas também que remete ao conjunto de indivíduos, permitindo que exista uma comparação entre eles. Nesse viés, nomeia-se de anormal aquele cuja diferença em relação à maioria seja perceptível. Tal contraste passa a ser considerado um desvio, algo indesejável. Além disso, a norma é saturante, fazendo de todos um caso médico: o normal e o anormal. Nesse sentido, o anômalo também está abrigado na norma, ainda que seja tomado como um oposto ao normal e, por isso, torna-se um sujeito passível a um tratamento e a um posterior processo de cura.

6. De acordo com Álvarez-Uria e Varela ( $199 \mid$ ), após o Renascimento o processo de pedagogização dos conhecimentos ganhou uma significativa importância na sociedade ocidental, principalmente após 
sário cuidar das crianças, dizer-lhes o que podem ou não fazer, dando-lhes regras precisas a serem seguidas. Era preciso ensinar a infância a governar-se, controlar os impulsos, comportar-se de acordo com as normas e refletir sobre as causas e as consequências dos próprios atos. Assim, a escola seria o lócus ideal para o desenvolvimento de tais aptidões.

É interessante salientar, também, que, conforme aponta Laqueur ( 1994), o final do século XVIII e início do XIX coincidiam com o período no qual o padrão de dois sexos estava sendo editado. A visão de sexo único (one sex-model), predominante até então, concebia as diferenças entre homens e mulheres apenas como divergências de grau. Ser homem e ser mulher estava determinado pelo lugar social, e não por suas diferenças anatômicas e biológicas. Somente a partir do século XVIII, com o fortalecimento do discurso medicalizado, é que surge o two sex-model. Assim, acaba-se por definir, de maneira binária, os papéis sociais e, principalmente, heterossexuais, que tanto homens quanto mulheres deveriam ocupar neste novo modelo urbano, capitalista e industrial. ${ }^{7}$

Tal dicotomia, baseada numa heterossexualidade compulsória, ${ }^{8}$ se materializou nos discursos dos principais pedagogos iluministas. De acordo com Soares ( 1994), Pestalozzi (1746- | 827), num livro denominado "Como Gertrudes educa seus filhos", destacou que o modelo para o ensino escolar teria que derivar do ensino familiar. Essa conduta, em comparar o estabelecimento educativo ao ambiente familiar, foi fundamental para a generificação docente e a difusão da matriz hetero como norma a ser seguida.

a "invenção" da concepção de infância. Foi nesse período que surgiu a necessidade de separar rigidamente, através de toda uma maquinaria, o mundo dos adultos do das crianças; e a escola seria o lócus ideal para estas novas formas de educação. Todas essas técnicas e procedimentos converteram-se em importantes ferramentas de extração de saberes dos corpos infantis, tornando-se fonte de exercícios de poderes que extraem verdades a respeito destes corpos e possibilitam o surgimento de uma "ciência pedagógica".

7. Weeks (1999, p.43) explica de forma didática como se constroem essas definições que vão marcar os modelos duais de sexo, bem como o exercício da sexualidade dos corpos dos indivíduos: (I) sexo - termo descritivo para as diferenças anatômicas básicas, internas e externas ao corpo, que se vê como diferenciando homens e mulheres; (2) gênero - termo usado para descrever a diferenciação social entre homens e mulheres; (3) sexualidade - descrição geral de crenças, comportamentos, relações e identidades socialmente construídas e historicamente modeladas em relações aos seus desejos e prazeres sexuais.

8. Butler (2003) argumenta que a heterossexualidade compulsória surge como um mecanismo regulador de práticas e definidor de papéis restritos aos desenhos anatômicos e genitais masculinos e femininos, sendo ela produtora daquilo que é "certo" ou "errado", quanto aos usos dos corpos nas relações sociais e culturais. 


\begin{abstract}
Os meninos na escola aprendem a reafirmar sua identidade masculina heterossexual como parte de um guia oficial e institucional. Isto se dá a partir de um conjunto de disciplinas escolares cujos símbolos e imagens transmitem, distribuem e colocam em circulação a idéia de sexualidade como um aspecto meramente reprodutivo (o pênis ejacula no interior da vagina e em determinadas condições se gesta a vida), o conceito de família nuclear tradicional (pai e mãe como as únicas figuras possíveis), a classificação de esposa e esposo com estatutos diferentes e excludentes em que só o pai cumpre com a três funções básicas que definem a masculinidade hegemônica adulta moderna: procriar, prover e proteger. (SCHARAGRODSKI; NARODOWSKI, 2006, p. I I 4).
\end{abstract}

Para operacionalizar tais questões, surgiram, nesse momento histórico, os primeiros procedimentos para a configuração do modelo escolar difundido em todo o mundo ocidental: a organização em disciplinas escolares, o surgimento do currículo, a organização do tempo e dos espaços dos exercícios e o início da formação docente. (ALVAREZ-URIA; VARELA, 199I; DUSSEL; CARUSO, 1999. PINEAU, et. al., 2005). Contudo, o aspecto central apresentado pela escola do final do século XVIII, foi a ordenação dos alunos por idade, grau de conhecimento e, sobretudo, pela separação em sexo biológico (CÉSAR, 2004). Fatos estes que fornecem indícios poderosos para se afirmar que o currículo é, também, uma importante maquinaria generificante.

Currículo é um dos dispositivos que concentra complexas relações entre a cultura e a escola, entre os saberes e as práticas socialmente construídas e os conteúdos escolares vinculados com certo tipo de masculinidade e feminilidade adequada, correta e verdadeira. (SCHARAGRODSKY; NARODOWSKI, 2006, p. I I3).

Dentro dessa maquinaria, ganha destaque uma disciplina escolar denominada Educação Física que, conforme lembra Soares (1994), teve como primeiro conteúdo trabalhado em suas aulas uma prática corporal chamada Ginástica.

\title{
MAQUINARIA II: A GINÁSTICA
}

No que concerne à constituição da Educação Física, ou melhor, dizendo da Ginástica, os filósofos e pedagogos iluministas também deram sua contribuição. Soares ( 1994) afirma que Pestalozzi considerava a presença dos exercícios físicos fundamentais para os processos de escolarização, principalmente por sua utilidade na disciplinarização e no proveito moral que tal prática poderia exercer sobre as crianças. Além de Pestalozzi, outros pensadores foram centrais para o desenvolvimento da Ginástica como disciplina escolar - destaque para os pedagogos alemães representantes daquilo que, no início do século XIX, veio a ser chamado de Ginástica Alemã. Soares (1994) argumenta que, nesse período, ainda não havia ocorrido a unidade 
territorial dessa nação, e, para que a Alemanha atingisse a unificação, foi preciso produzir um forte espírito nacionalista com homens fortes, robustos e saudáveis. Esse "corpo masculino saudável" seria produzido através da Ginástica, construída a partir de bases científicas, em especial sobre os saberes oriundos da fisiologia e da anatomia, os quais prescreviam práticas diferenciadas para meninos e meninas.

Outra vertente, importante para a configuração da Educação Física como disciplina escolar, foi a Escola Sueca. Imersa nas mesmas condições de possibilidade da nascente sociedade industrial, a sistematização ginástica realizada na Suécia visava ser um instrumento capaz de criar indivíduos fortes e saudáveis. Assim como o método alemão, tal concepção baseava-se na ciência médica, principalmente no saber oriundo dos campos da anatomia e da fisiologia.

Segundo Soares (1994), foi na França que surgiu o maior movimento ginástico do século XIX: a Escola Francesa. A ginástica francesa, assim como as duas outras escolas, se baseava na medicina e na biologia. Tal prática deveria ser ofertada e organizada pela instituição escolar, e necessitava ter como base os saberes médicos. O pedagogo, biólogo e fisiologista Demeny (1850-1917), um defensor da ciência, acreditava que a ginástica deveria se basear em resultados de experiências realizadas a partir de um método científico muito rigoroso, e não mais em procedimentos empíricos. Foi também um dos primeiros teóricos a se preocupar com os exercícios físicos para as mulheres, buscando sistematizar e organizar as atividades que mais se "adequassem à natureza" reprodutora feminina, visto que seriam elas as geradoras dos filhos da pátria - sendo o bom soldado, o operário e o elegante e civilizado cidadão liberal. Surgem com Demeny as bases para generificação do currículo em Educação Física, o qual, amparado no pensamento médico, deu início à separação por sexo dos indivíduos nas aulas de Ginástica na escola. No que se refere a essa separação, os exercícios físicos para as mulheres deveriam ser adaptados à "natureza" frágil das futuras mães, ou seja, a prescrição de atividades físicas voltadas para o público feminino deveria sempre buscar a construção de um corpo apto à reprodução. ${ }^{9}$ Tais fatores acabavam por difundir com muita força a matriz hetero como norma a ser seguida pelos indivíduos.

Apesar das diferenças, os métodos ginásticos eram muito parecidos entre si, pois suas bases eram ditadas pelas ciências biológicas. Todos possuíam um caráter instrumental, no qual o exercício físico surgia como um antídoto para os males

9. De acordo com Soares (1994), várias figuras proeminentes do Brasil do início do século XX discutiam a questão da prescrição de exercícios físicos para as mulheres. Destaque especial para Fernando de Azevedo e o eugenista Renato Kehl. Para uma análise mais detalhada sobre o pensamento de Fernando de Azevedo, consultar o artigo de Goellner e Fraga (2004). No que se refere a Renato Kehl, indica-se o trabalho de Silva e Goellner (2008). Sobre a relação entre o saber médico argentino e a inserção das mulheres nas práticas corporais, recomenda-se o artigo de Scharagrodsky (2008). 
sociais, além de um importante elemento na prevenção de doenças, na construção do corpo saudável e na disciplinarização para as diversas esferas da vida. Assim, a ginástica tornava-se, segundo Soares (2006), uma prática fundamental para desenvolver tanto a disciplinarização dos corpos no plano individual (poder disciplinar), como para organizar o corpo social (biopolítica).

\footnotetext{
Pode-se afirmar, assim, que a ginástica é parte desta cartografia do detalhe, ela atua nos mais íntimos espaços do corpo e indica os mais variados comportamentos, conformando modos de viver; ela integra procedimentos educativos, aqueles mesmos exigidos nos processos de trabalho industrial (...). A ginástica é esta pedagogia que incide sobre o corpo individual e auxilia na regulagem das populações, é tanto disciplina quanto regulamentação da vida ... (SOARES, 2006, p. 78-79).
}

Assim, a escola passou não só a disciplinar o corpo individual, como também a regular o corpo-espécie. Nesse processo, o saber científico, sobretudo o oriundo dos conhecimentos médicos e biológicos - tão importantes para a construção dos modelos masculinos, femininos e da matriz hetero -, torna-se fundamental, visto que foi nesse período histórico que ocorreu um amplo esforço para normatizar, ordenar e classificar todas as ações e saberes. Nos processos de escolarização não foi diferente, pois a norma também se fazia presente, e a Ginástica tornou-se uma importante engrenagem da maquinaria chamada escola.

Contudo, como lembra Soares (2006), uma nova manifestação cultural - o Esporte - surge no campo da Educação Física e passa a fazer parte dos currículos escolares.

\section{MAQUINÁRIA III: O ESPORTE}

No fim do século XIX, surge uma nova manifestação cultural que acaba por se tornar o principal aspecto a ser trabalhado nas aulas de Educação Física: o esporte. Foi nesse momento histórico que surgiram as bases do Esporte Moderno que, apesar de ter diferenças significativas em relação aos fundamentos básicos da ginástica, continuava sendo, conforme aponta Soares (2006), uma pedagogia higiênica que visava a um investimento ainda maior na intimidade e no controle biopolítico dos corpos.

Esse controle sobre a vida também se evidencia nos aspectos de gênero, pois o Esporte tornou-se algo ainda mais separador, sexista e difusor da heterossexualidade do que a Ginástica. Essas afirmações podem ser comprovadas nos trabalhos de Rial (1998), Scharadrodski (2002), Liotard (2003), Anderson et. al. (2005), Rosa (2008) e Moraes e Silva (2008), visto que todos estes autores afirmam que os esportes são um território masculino por excelência. 
esporte é um espaço estratégico para o estudo das masculinidades e das relações de gênero. $\bigcirc$ esporte e a masculinidade vinculam-se intimamente nas sociedades ocidentais, desde as Olimpíadas gregas e os tempos romanos até as ordens modernas e pós-modernas de gênero. Culturalmente, o esporte tem sido um terreno onde a masculinidade se comprova, uma 'escola' na qual se aprende a valorizar o 'ser homem' (manhood) e a desvalorizar o 'ser mulher' (womanhood), um espaço cultural onde, muito frequentemente, os meninos e os homens aprendem a se enaltecer desvalorizando os homens fisicamente mais fracos e as mulheres. (SABO, 2002, p. 34).

Esse fato aproxima o esporte a um ritual de confirmação da virilidade e da preservação da matriz hetero. As cerimônias esportivas visam realizar a separação dos meninos das mães, assegurando, assim, uma masculinização progressiva que busca prepará-los para uma inserção na vida adulta, mantendo-os a uma distância segura do universo feminino.

\begin{abstract}
A Educação Física nasce para abarcar um conjunto de práticas corporais pertencentes a um mundo reconhecidamente masculino - virilidade, agilidade e força são habilidades tipicamente masculinas - concebidas a partir do isolamento do sexo como aparato biológico. Ideias de que os corpos das mulheres são desdobramentos mal elaborados ou incompletos do masculino e que, portanto, apresentam debilidades e fragilidades persistem ainda nos dias atuais e se expressam através de crenças também pautadas nas Ciências Biológicas de que a elas resta os destinos da maternidade e do cuidado doméstico para com os filhos e filhas. (SAYÃO, 2002, p. 90-91).
\end{abstract}

As mulheres que quisessem participar de práticas esportivas teriam que quebrar importantes fronteiras de gênero, pois, além de manterem a divisão de turmas por sexo, ${ }^{10}$ os códigos dessas práticas eram masculinizados (ALTMANN, 1998). Sabo (2002, p.36-37) resume muito bem a presença de atitudes de depreciação feminina no campo esportivo:

A desvalorização das mulheres no esporte fica evidente no simples fato de que a maior parte dos meninos e dos homens considera que é superior às mulheres no esporte - seja ou não realidade. Se os esportes frequentemente ensinam os meninos a se considerar superiores às mulheres, muitos meninos também aprendem a evitar aquilo que a cultura define como atividades ou características femininas. Ironicamente, uma grande parte da iniciativa de meninos e de homens a se conformarem ao ideal masculino provém nem tanto do desejo de ser viril (macho, manly), mas o medo de ser visto como pouco viril ou como feminino.

I0. Segundo argumentam Louzada et. al. (2007), após a Segunda Guerra Mundial, o conteúdo esporte como método de educação física desportiva generalizada passou a ser hegemônico no Brasil. Essa proposta, assim como a ginástica, recomendava a separação entre os meninos e as meninas, pois objetivava um maior rendimento e aptidão física. Tais questões se materializaram na Lei de Diretrizes e Bases da Educação Nacional (LDB), escrita em 1971, visto que tal documento recomendava a separação pelo sexo nas aulas de Educação Física. 
Nesse sentido, a heterossexualidade se manifesta no mundo esportivo transformando as práticas corporais em um espaço de categorizações, em que corpos masculinos e femininos raramente se misturam. Trata-se de um lócus de afirmação de certos valores masculinos, conforme levanta Liotard (2003, p.3):

A classificação histórica dos corpos, conforme esta economia da performance coloca o modelo do macho conquistador como ideal corporal, e faz do mundo dos esportes uma espécie de clausura onde se perpetua e se difunde o patrimônio viril.

Essa predominância do masculino desempenha papel fundamental na economia de controle dos corpos, porque contribui para o estabelecimento de espaços e práticas sociais diferenciados, tanto para aqueles e aquelas capturados pela biopolítica e pela matriz heterossexual, quanto para os demais que, de alguma forma, desviam-se da norma.

Conforme aponta Soares (2006), os esportes foram e continuam sendo um modo eficaz encontrado pela biopolítica para executar a produção do corpo-espécie e, por que não falar, para fabricar seres generificados através de suas práticas sexistas, presentes nos conteúdos das aulas de Educação Física. Contudo, no início dos anos 1980, surge uma nova fase no pensamento pedagógico da Educação Física brasileira, que passa a questionar o papel até então realizado por esta disciplina escolar.

\section{À GUISA DE UMA CONCLUSÃO: CONTESTANDO AS CONTRUÇÕES DE GÊNERO NA EDUCAÇÃO FÍSICA}

Uma nova fase surge no campo teórico da Educação Física brasileira no início da década de 1980, pois, a partir de então, iniciou-se uma aproximação a novos discursos, que iam além do paradigma da aptidão física (SOARES, et.al. 1992). Um dos maiores méritos das propostas pedagógicas elaboradas após esse período, além da crítica à visão biológica e à esportivização excessiva das aulas, foi ter iniciado uma preocupação com os aspectos culturais, entre eles as questões relativas aos aspectos de gênero. Conforme apontam Louzada et. al. (2007), foi através desse discurso que se acentuou o debate sobre a dicotomia misto/separado. A forte tendência em defender as turmas mistas contribuiu para que, nos finais dos anos de 1990, tal prescrição se materializasse nos Parâmetros Curriculares Nacionais (PCN's). Essa discussão da separação, ou da utilização das aulas mistas e/ou co-educativas, foi central para compreender como os aspectos de gênero são produzidos no interior das aulas de Educação Física. "

I I. Deve-se entender que as aulas mistas e as co-educativas possuem diferenças significativas, pois as primeiras não necessariamente prezam pela igualdade de oportunidades entre meninos e meni- 
Fruto do contato com esse novo discurso, surge uma primeira literatura a respeito do assunto na Educação Física escolar no país. Destaque para os estudos de Romero (1992; 1994), Chagas (1994), Abreu (1995), Ferreira (1996) e Saraiva ( 1999$)$. Contudo, tais produções - apesar de terem o mérito de lançar a questão das diferenças entre os sexos e o conceito de gênero nas produções brasileiras sobre Educação Física escolar -, não avançaram na crítica à matriz hetero. Fato que acaba por reproduzir a dicotomia no que se refere às questões de gênero, ou seja, tais produções continuavam a pensar o homem e a mulher como categorias genéricas e universais amarradas ao discurso da matriz hetero e, por que não falar, de uma biopolítica.

O aprofundamento e as problematizações sobre as questões de gênero só apareceriam em meados dos anos de 1990, pois, conforme aponta Louro (2004), foi somente neste período que os princípios do currículo começaram a ser contestados pelos estudos culturais, bem como pelas teorias pós-críticas e pós-estruturalistas. Sendo que estas eram alimentadas intelectualmente pelos emergentes movimentos feministas, étnicos, gays com sua teoria queer ${ }^{2}$ e pós-colonialistas.

No campo da Educação Física escolar, o debate multicultural e de contestação do currículo levou ao surgimento de uma série de trabalhos que aproximaram o campo a esse novo discurso político. No quesito gênero, destaque especial para os trabalhos de Altmann (1998), Sayão (2002) e Dornelles (2007). Contudo, mais recentemente surgem pesquisas que questionam não somente as questões de gênero, como também toda a matriz hetero (ROSA, 2008; MORAES; SILVA, 2008). Estudos estes que trazem novos elementos para o debate e possibilitam repensar os caminhos pedagógicos da Educação Física brasileira, visto que passam a pensar as relações entre os sexos para além da heterossexualidade, mostrando que novas formas de existência podem ser criadas a partir do espaço escolar e das aulas de Educação Física.

nas. Essa característica é o objetivo central nas co-educativas. As aulas mistas têm como principal particularidade o simples fato das aulas serem feitas conjuntamente entre homens e mulheres.

12. De acordo com Louro (2004), queer pode ser traduzido por estranho, ridículo, raro ou extraordinário. A autora lembra que essa expressão também pode se constituir de uma maneira pejorativa, com que são designados homens e mulheres homossexuais. Sendo assim, a teoria queer está relacionada com a produção teórica de intelectuais engajados (as) no movimento homossexual, principalmente nas reflexões advindas das teóricas lésbicas, que passaram a questionar com muita ferocidade a matriz hetero. 
Physical education and school: disciplinary machinery, biopolitics and gendering

ABSTRACT: This work aims to show the way the process of schooling and the discipline of Physical Education helped to produce and generate male and female behavior. To achieve this purpose, this research is based on the genealogical reflections of Michel Foucault. In conclusion, the study indicates that the Physical Education, through the practices of Gymnastics and Sports, has contributed significantly to the construction of this dual model in the process of schooling.

KEYWORDS: School; Physical Education; Biopolitics; gender.

\section{La Educación Física y la escuela: maquinaria disciplinar, biopolítica y generificante}

RESUMEN: Este trabajo intenta mostrar cómo el proceso de la escolarización y la disciplina de la Educación Física ayudaron a producir y generar comportamientos masculino y femenino. Para lograr este propósito, se basa en la reflexión genealógica de Michel Foucault. En conclusión, el estudio indica que la Educación Física, mediante prácticas de Gimnasia y Deportes, ha contribuido significativamente a la construcción de este modelo dual en los procesos de escolarización.

PALABRAS CLAVE: Escuela; Educación Física; biopolítica; género.

\section{REFERÊNCIAS}

ABREU, N. G. Análise das percepções de docentes e discentes sobre as turmas mistas e separadas por sexo nas aulas de Educação Física escolar. In: ROMERO, E. (Org.). Corpo, mulher e sociedade. Campinas: Papirus, 1995. p. 157-176.

ÁLVAREZ-URIA, F;; VARELA, J. Arqueologia de la escuela. Madrid: La Piqueta, 1991.

ALTMANN, H. Rompendo fronteiras de gênero: Marias (e) homens na Educação Física. I I 0 f. Dissertação (Mestrado em Educação) - Faculdade de Educação, Universidade Federal de Minas Gerais, Belo Horizonte, 1998.

ANDERSON, E. et al. In the game: gay athletes and the cult of masculinity. Albany: State University of New York, 2005.

BUTLER, J. Problemas de gênero: feminismo e subversão da identidade. Rio de Janeiro: Civilização Brasileira, 2003.

CÉSAR, M. R. de A. Da escola disciplinar à pedagogia do controle. 2004. 190 f. Tese (Doutorado em Educação) - Faculdade de Educação, Universidade Estadual de Campinas, 2004. 
CHAGAS, E. P. Educação Física: Escola de... formação do corpo feminino. Revista Brasileira de Ciências do Esporte, ljuí, v. I5, n. 3, p. 253-262, jan./jun. 1994.

DORNELLES, P. G. Distintos destinos? A separação entre meninos e meninas na Educação Física escolar na perspectiva de gênero. 2007. I 56 f. Dissertação (Mestrado em Educação) Faculdade de Educação, Universidade Federal do Rio Grande do Sul, Rio Grande do Sul, 2007.

DUARTE, A. M. Sobre a biopolítica: de Foucault ao século XXI. Revista Cinética, v. I, p. I- | 6, 2008.

DUSSEL, I.; CARUSO, M. La invención del aula: una genealogía de las formas de enseñar. Buenos Aires: Saintillana, 1999.

FERREIRA, J. L. As relações de gênero nas aulas de Educação Física: um estudo de caso em uma escola pública de Campina Grande. 1996. I4I f. Dissertação (Mestrado em Educação) -Faculdade de Educação, Universidade Federal da Paraíba, João Pessoa, 1996.

FOUCAULT, M. Historia da sexualidade I: à vontade de saber. Rio de Janeiro: Grall, 1998. Vigiar e punir: o nascimento da prisão. Petrópolis: Vozes, 2002.

GOELLNER, S. V.; FRAGA, A. B. A inominável Sadwina e as obreiras da vida: silêncios nas obras inaugurais de Fernando de Azevedo. Revista Brasileira de Ciências do Esporte, Campinas, v. 25, n. 2, p. 7I-84, jan. 2004.

LAQUEUR, T. La construcción del sexo: cuerpo y gênero desde los griegos hasta Freud. Madrid: Cátedra, 1994.

LIOTARD, P. Sport et homophobie. In: TIN, L. Dictionaire de l'homophobie. Paris: Universitaires de France, 2003. p. 383-386.

LOURO, G. L. Um corpo estranho: ensaios sobre sexualidade e teoria queer. Belo Horizonte: Autêntica, 2004.

LOUZADA, M. et. al. Representações de docentes acerca da distribuição dos alunos por sexo nas aulas de Educação Física. Revista Brasileira de Ciências do Esporte, Campinas, v. 28, n.2, p.55-68, jan. 2007.

MORAES E SILVA, M. Entre a ilha deserta e o arquipélago: mapeamentos e cartografias das percepções de professores (as) sobre as masculinidades produzidas nas aulas de Educação Física. 215 f. Dissertação (Mestrado em Educação) - Universidade Federal do Paraná, Curitiba, 2008.

PINEAU, P. et al. La escuela como máquina de educar: tres escritos sobre un proyecto de la modernidade. Buenos Aires: Paidós, 2005.

RIAL, C. S. M. Rúgbi e judô: esportes e masculinidades. In: PEDRO, J. M.; GROSSI, M. P. (Org.). Masculino, feminino, plural: gênero na interdisciplinaridade. Ed. Mulheres, Florianópolis, 1998. p.229-258. 
ROMERO, E. Diferenças entre meninos e meninas quanto aos estereótipos: contribuição para uma política de desmitificação. Revista Brasileira de Ciências do Esporte, ljuí , v. I4. n. I, p. 24-28, set. 1992.

Educação Física a serviço da ideologia sexista. Revista Brasileira de Ciências do Esporte, ljuí, v. I5. n. 3, p. 226-234, jun. 1994.

ROSA, R. B. C. Homofobia e esporte na produção da educação física brasileira (1979-2007). 2008. 54 f. Trabalho de Conclusão de Curso (Graduação em Educação Física) - Faculdade de Educação Física, Universidade Estadual de Campinas, Campinas, 2008.

SABO, D. O estudo crítico das masculinidades. In: ADELMAN, M.; SILVESTRIN, C. B. (Org.). Coletânea gênero plural. Curitiba: Ed. da UFPR, 2002. p. 33-46.

SARAIVA, M. C. Co-educação física e esportes: quando a diferença e mito. ljuí: Ed. da UNIJUÍ, 1999.

SAYÃO, D. T. Por que investigar as questões de gênero no âmbito da Educação Física, esportes e lazer? Motrivivência, Florianópolis, n. 19, p. 87-95, dez. 2002.

SCHARAGRODSKY, P. A. Los graffitis y los cánticos futboleros platenses: acerca del processo de configuración de diversas masculinidades. Revista Brasileira de Ciências do Esporte, Campinas, v. 24, n. I, p. 179-197, set. 2002.

Entre la maternidad y la histeria. Medicina practicas corporales e feminidad en el Buenos Aires del fin del siglo XIX. In: SCHARAGRODSKY, P. A. (Org.). Gobernar es ejercitar: fragmentos para una historia de la Educación Física en Iberoamérica. Buenos Aires: Prometeo, 2008, v. I. p. 105-136.

.; NARODOWSKI, M. Investiagación educativa y masculinidades: más allá del feminismo más acá de la testosterona. In: NARODOWSKI, M.; BRAILOVSKY, D. Dolor de escuela. Buenos Aires: Prometeo, 2006. p. 107- 129.

SILVA, A. L. dos S.; GOELLNER, S. V. Sedentárias e coquettes à margem: corpos e feminilidades desviantes na obra de Renato Kehl. Pensar a Prática, Goiânia, v. I I, p. 50-63, set./ dez. 2008.

SOARES, C. L. et al. Metodologia do ensino da Educação Física. São Paulo: Cortez, 1992.

SOARES, C. L. Educação Física: raízes européias e Brasil. Campinas: Autores Associados, 1994.

SOARES, C. L. Pedagogias do corpo: higiene, ginásticas, esporte. In: RAGO, M.; VEIGA NETO, A. (Org.). Figuras de Foucault. Belo Horizonte: Autêntica, 2006. p. 75-85.

VEIGA NETO, A. Foucault \& a educação. Belo Horizonte: Autêntica, 2004.

Dominação, violência, poder e educação escolar em tempos de império. In:

RAGO, M.; VEIGA NETO, A. Figuras de Foucault. Belo Horizonte: Autêntica, 2006. p. I3-38. 
WEEKS, J. O corpo e a sexualidade. In: LOURO, G. L. O corpo educado: pedagogias da sexualidade. Belo Horizonte: Autêntica, 1999. p. 35-82

Recebido: 4 ago. 2010 Aprovado: 3 fev. 2011

Endereço para correspondência:

Marcelo Moraes e Silva Rua Martin Afonso, 226 ap. 3A CEP 804 I 0-060 Bairro São Francisco - Curitiba PR 